\title{
STATIC AND BUCKLING ANAL YSIS OF ISOGRID STRUCTURES FOR AEROSPACE APPLICATIONS
}

\author{
Supriya ${ }^{1}$ and S. Venkat Prasat $^{2}$ \\ ${ }^{1}$ P.G. Student (CAD/CAM), Department of Mechanical Engineering,NallaMalla Reddy \\ Engineering College, Hyderabad, Telangana, India \\ ${ }^{2}$ Professor, Department of Mechanical Engineering,NallaMalla Reddy Engineering College, \\ Hyderabad,Telangana, India
}

\begin{abstract}
Isogrid structuresare typically found in critical components that require high stiffness and whichresist buckling loads. The isogrid structure consists of a thin outer skin that employs a repetitive equilateral triangular pattern of stiff ribs.In this research work, experiments were carried out to evaluate the strength of the three isogrid cylinders with different materials (carbon fiber,e-glass fiber and aramid fiber). The objective of this research work is to determine the best materialamong them and to optimize the structure under various loads $(250$ $\mathrm{N}, 500 \mathrm{~N}$ and $750 \mathrm{~N}$ ). Static and buckling analyses wereconducted to determine the deformation, stress, strain and buckling load factor for the isogrid structure. Modeling was performed using ANSYS design modeler parametric software and analysis was done using ANSYS. It was determined from the analyses that the aramid fiber material exhibited the least value of deformation, stress and strain when compared to e-glass fiber and carbon fiber.It was concluded from the static and buckling analysis that aramid fiber material is the best suitable material for fabricating an isogrid structure for aerospace applications.

Keywords:Isogrid structure, Aramid fiber, ANSYS, Static analysis, Buckling analysis.
\end{abstract}

Corresponding Author:S. VenkatPrasat

\section{INTRODUCTION}

The search for lightweight and efficient aerospace and aircraft structural component is an ongoing process in the industry and one such design is the composite isogrid structure. Such structures are adopted in the aeronautical industry since they present both structural resistance and lightness. They arealso less susceptible to impact damage. Isogrid structures are constituted by a thin skin reinforced with a lattice structure. Isogrid is a type of partially hollowed-out structure formed usually from a single metal plate (or face sheet) with triangular integral stiffening ribs (often called stringers). It is extremely light and stiff. The triangular pattern is very efficient since it retains high rigidity while saving material, weight and cost. Compared to other materials, it is expensive to manufacture and so it is restricted to spaceflight applications and some particularly critical parts of more general aerospace use. Figure 1 displays the top view of the isogrid panel.

Isogrid structures are related to sandwich-structured composite panels; both can be modeled using sandwich theory, which describes structures with separated, stiff face sheets and a lighter interconnecting layer. Isogrids are manufactured from single sheets of material and with large-scale triangular openings. They have an open pattern to the flanges, compared to closed sheets and foam or honeycomb structures for the sandwich-composite structures. 


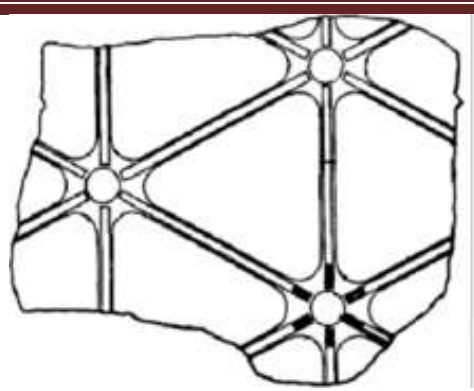

Fig No 1 : Top view of isogrid panel

\subsection{Applications}

Isogrid panels form self-stiffened structures where low weight, high stiffness and strength are required in aircraft or space vehicles. Aerospace isogrid structures include payload shrouds and boosters, which must support the full weight of upper stages and payloads under high $\mathrm{G}$ loads. Their open configuration with a single sealed sheet facing the outside makes them especially useful as propellant tanks for rockets.

Composites are made up of individual materials referred to as constituent materials. There are two main categories of constituent materials: matrix (binder) and reinforcement. The matrix material surrounds and supports the reinforcement materials by maintaining their relative positions. The reinforcements impart their special mechanical and physical properties to enhance the matrix properties. A synergism produces composite material properties that were initially unavailable from the individual constituent materials. A wide variety of matrix and strengthening materials allows the designer of the product or structure to choose an optimum combination.

\section{LITERATURE REVIEW}

In this research work, a typical study was done on isogrid and orthogrid type of structures which comprises of ribs that are arranged in helical and orthogonal pattern[1]. Orientation effect as well as the effect on outward and inward placement of ribs was studied by the researchers. Rib and skin thickness were varied for different load cases and were analyzed for static and buckling loads. Different failure modes were estimated based on the finite element analysis. MSC Nastran FE tool was used for analysis and the results were compared with analysis conducted using finite element software FEAST. From this study, it was concluded that buckling factor was high for orthogrid and isogrid structures when ribs were placed externally.

A structural optimization method was employed to design the spacecraft with the help of composite laminate isogrid structures[2]. This optimization method is shown to increase the structural performance by over $20 \%$. Several finite element analyses were conducted by the researchers to verify the structural integrity. They correlated these analyses with several static and modal tests to verify the models and the model boundary conditions. Environmental testing was performed on the integrated spacecraft at NASA Wallops Flight Facility to investigate the properties of the structural assembly.

Investigators designed an isogrid cylinder, made of composite material, fit to withstand well defined axial loads [3]. The design was carried out in two steps. In the first step, the Vasiliev theory was used to define the rib dimension of the lattice structure, while in the second step both material and thickness of the skin were determined by FEM. Then, the manufacturing process was designed, paying particular attention to the mould design and to the curing process. It was found out that the curing tools and the thermal cycle strongly affect the quality of the produced part. Finally, the designed part was produced and tested to assess the quality of the manufacturing process and the relevance to the design requirements. 
Isogrid structures show a high potential for weight saving in thin skin compression structure scenarios, which can be found in space launchers, satellites or similar applications[4]. However, the difficulties found in design, simulation and manufacturing these typeof structures with composite materials limit their use in comparison with other reinforcement solutions. Distributed sensing systems provide strain measurements all along a single optical fiber. It is possible to obtain the strain profile in different sections of the structure. This information will be useful to understand the buckling and non-linear behavior of complex composite structures.

Fiber-optic sensors cannot measure damage and to get information about damage from strain measurements, additional strategies are needed. Several such alternative strategies are available in the existing literature.A research paper discusses two independent procedures. The first procedure is based on detecting new strains appearing around a damaged spot[5].The technique is very robust and damage detectability is high, but it requires sensors to be located very close to the damage, so it is a local technique. The second approach offers wider coverage of the structure; it is based on identifying the changes caused by damage on the strain field in the whole structure for similar external loads.

\section{EXPERIMENTAL PROCEDURE}

Three isogrid cylinders with different materials like carbon fiber,e-glass fiber and aramid fiber were chosen for the study based on literature review. They were analyzed by applying various loads like 250 N,500 Nand 750 N.In this research work, modeling was performed using ANSYS designmodeler parametric software.ANSYS software is used for conducting analysis in order to solve the static and buckling problems.

\subsection{Design Specifications forIsogrid Structure}

A set of key points were defined that defines the geometry of the structure. These points were joined by using lines and subsequently areas were created by using these lines. Then these areas wereconverted into a 3D model.The dimensions of the isogridcylinder are given below:

- Diameter $=63.54 \mathrm{~cm}$

- Height $=36.40 \mathrm{~cm}$

- $\quad$ Rib breadth $(b)=1.45 \mathrm{~cm}$

- Rib thickness $(\mathrm{t})=0.17 \mathrm{~cm}$

Figure No.2 displays the 2D drawing of an Isogrid structure with dimensions.
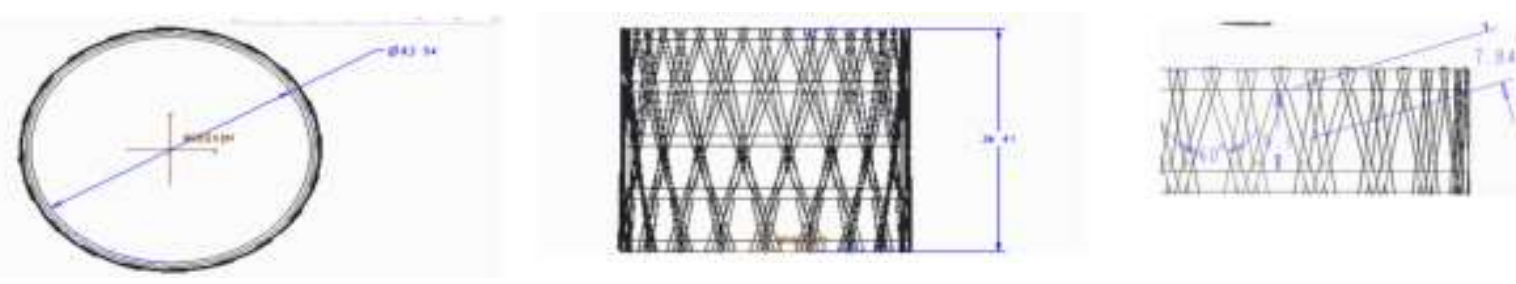

FigNo.2 : 2D drawing Iso grid structure

\subsection{Static And Buckling Analysis using ANSYS}

ANSYS is general-purpose finite element analysis (FEA) software package. Finite Element Analysis is a numerical method of deconstructing a complex system into very small pieces (of user-designated size) called elements. The software implements equations that govern the behaviour of these elements and solves them all; creating a comprehensive explanation of how the system acts as a whole. These results then can be presented in tabulated or graphical 
forms. This type of analysis is typically used for the design and optimization of a system which is far too complex to analyze manually. Systems that may fit into this category are too complex due to their geometry, scaleor governing equations.

\subsubsection{Static Analysis}

Static analysis determines the displacements, stresses, strains and forces in structures or component caused by loads that do not induce significant inertia and damping effects. Steady loading and response conditions are assumed, where the loads and the structure's response are assumed to vary slowly with respect to time.

\subsubsection{Buckling Analysis}

Buckling analysis is a technique used to determine buckling loads andcritical loads at which a structure becomes unstable. The analysis is also used to determine thebuckled mode shapes and the characteristic shape associated with a structure's buckled response.These steps involve solving the Eigen valve problem given in the Equation (1). This equation takes into consideration the pre-buckling stress effect matrix [s] calculated in the first step.

$([\mathrm{K}]+[\mathrm{S}])\{\mathrm{I}\}=\{0\}$

where $[\mathrm{K}]$ is the stiffness matrix, $[\mathrm{S}]$ is the stress stiffness matrix,I is the ith Eigen value (used to multiply the loads that generated [S]),I is the ith eigenvector of displacements.

The block Lancosmethod is used to extract the Eigen values resulting from Equation (1). The critical buckling load is then calculated according to Equation (2).

$\mathrm{P} \alpha=(\lambda \mathrm{i}) \min \mathrm{AP}$

where $(\lambda \mathrm{i}) \min$ is the minimum Eigenvalue, $\mathrm{A}$ is the total area on which pressure is applied,P is the initially applied pressure.

\section{RESULTS AND DISCUSSIONS}

Static and buckling analysis of isogrid structure was conducted using ANSYS software and the stress, strain and total deformation were determined for various materials.

\subsection{Static Analysis of Isogrid Structure}

Static analysis of the isogrid structure was conducted using ANSYS software and the stress, strain and total deformation were determined.

\subsubsection{Imported and Meshed model}

Static analysis of the isogrid structure was conducted using ANSYS software for three different materials, namely,carbon fiber, e-glass fiber and aramid fiber.The imported model of the isogrid structure is displayed in Figure No. 3.

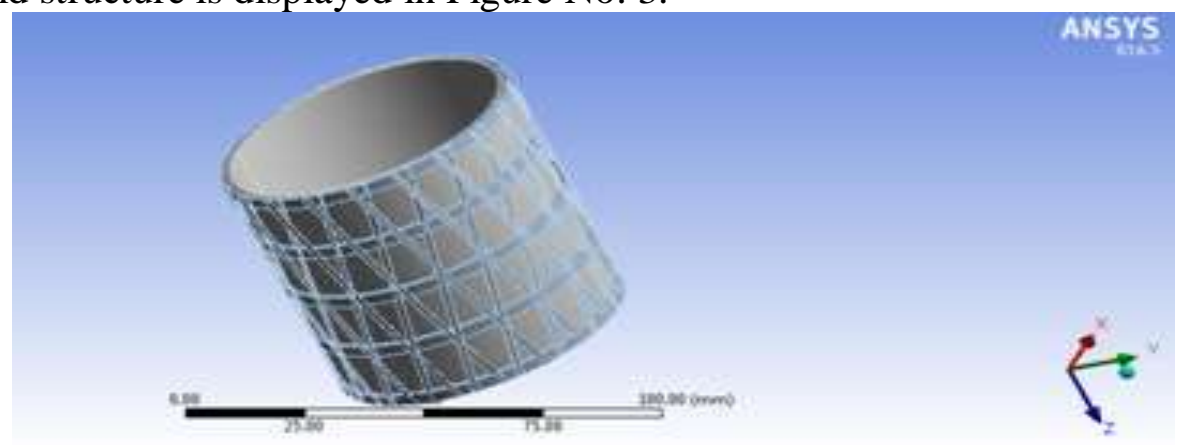

Fig No. 3: Imported model 
The meshed model of the isogrid structure is displayed in Figure No. 4.

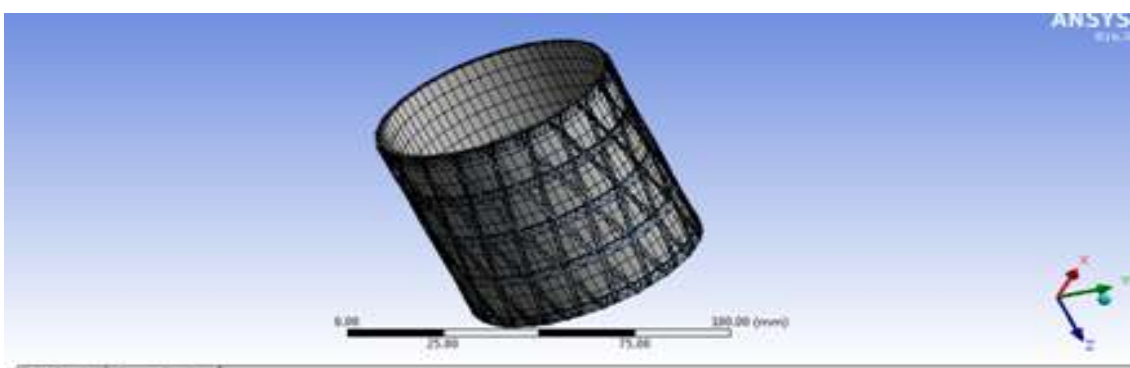

Fig No. 4 Meshed model

The number of nodes and elements are displayed in Table No.1.

Table No. 1 Number of nodes and elements

\begin{tabular}{|l|l|}
\hline Nodes & 47236 \\
\hline \hline Elements & 18929 \\
\hline
\end{tabular}

\subsubsection{Total deformation at load $250 \mathrm{~N}$}

A load of $250 \mathrm{~N}$ was applied to the isogrid structure and the total deformation was calculated using ANSYS. According to the counter plot which was obtained, the maximum deformation was found to occur at free end of the isogrid structure since one end of the isogrid was fixed.The maximum deformation obtained is $0.020275 \mathrm{~mm}$ and minimum deformation is $0.001003 \mathrm{~mm}$ for e-glass fiber material. The total deformation in the isogrid structure is shown in Figure No. 5.

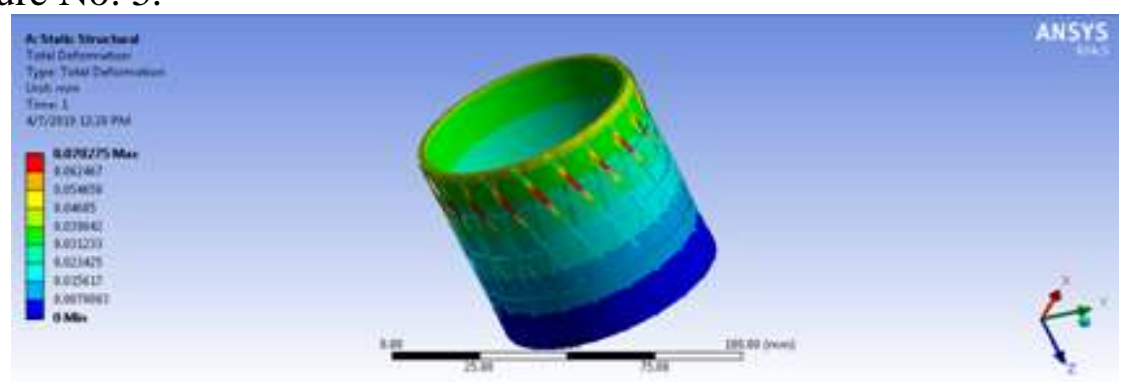

Fig No. 5: Total Deformation

\subsubsection{Stress}

According to the counter plot, the maximum stressoccured at fixed end of the isogrid structure since one end of the isogrid was fixed.The maximum stress was calculatedas $161.4 \mathrm{~N} / \mathrm{mm} 2$ whereas the minimum stresswas $0.042 \mathrm{~N} / \mathrm{mm} 2$ for e-glass fiber material.The stress induced in the isogrid structure is shown in Figure No. 6.

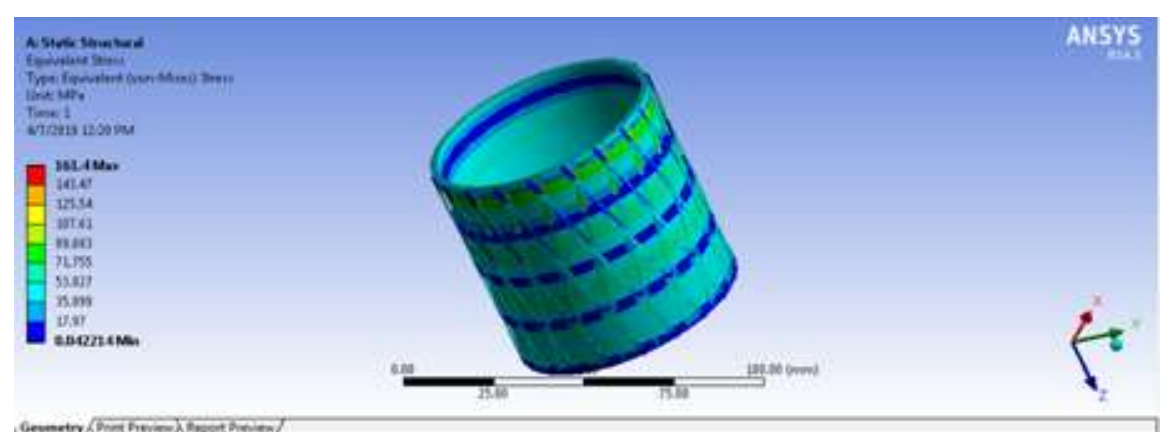

Fig No. 6: Stress 


\subsubsection{Strain}

According to the obtained counter plot, the maximum strain occurred at the fixed end of the isogrid structure since the one end of the isogrid was fixed. The maximum strain was estimated as 0.002346 whereas the minimum strainwasestimated as 0.000026491 for e-glass fiber material. The strain induced in the isogrid structure is shown in Figure No. 7.

Table No. 2 display the results of static analysis of isogrid structure with different materials like e-glass fiber, carbon fiber and aramid fiber. The deformation, stress and strain values were estimated using ANSYS software and the results for various load like $250 \mathrm{~N}, 500$ $\mathrm{N}$ and $750 \mathrm{~N}$ are displayed in Table No. 2. From these results it can be seen clearly that aramid fiber material exhibited the least values for deformation, stress and strain at various loads like $250 \mathrm{~N}, 500 \mathrm{~N}$ and $750 \mathrm{~N}$.

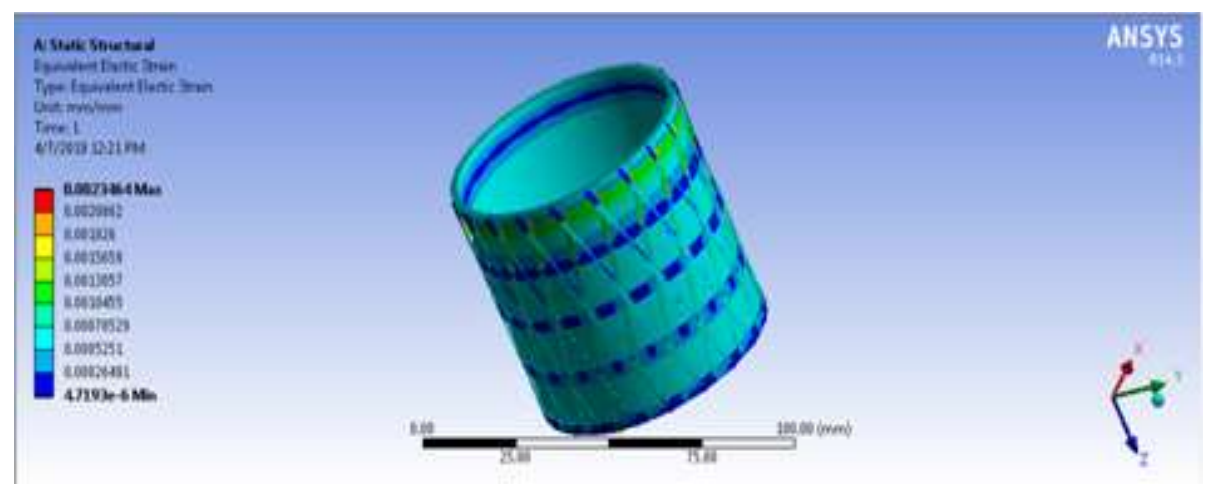

Fig No. 7: Strain

Table No. 2 Results of Static Analysis

\begin{tabular}{|l|c|c|c|c|}
\hline Material & $\begin{array}{c}\text { Load } \\
(\mathbf{N})\end{array}$ & $\begin{array}{c}\text { Deformation } \\
(\mathbf{m m})\end{array}$ & $\begin{array}{c}\text { Stress } \\
\left(\mathbf{N} / \mathbf{m m}^{\mathbf{2}}\right)\end{array}$ & Strain \\
\hline \multirow{2}{*}{$\begin{array}{l}\text { E-glass } \\
\text { fiber }\end{array}$} & $\mathbf{2 5 0}$ & 0.07025 & 161.4 & 0.0023464 \\
\cline { 2 - 5 } & $\mathbf{5 0 0}$ & 0.14055 & 322.79 & 0.0046929 \\
\cline { 2 - 5 } $\begin{array}{l}\text { Carbon } \\
\text { fiber }\end{array}$ & $\mathbf{7 5 0}$ & 0.21082 & 484.19 & 0.0070339 \\
\cline { 2 - 5 } & $\mathbf{5 0 0}$ & 0.1444 & 321.32 & 0.0048044 \\
\cline { 2 - 5 } & $\mathbf{7 5 0}$ & 0.2166 & 481.98 & 0.0072066 \\
\hline \multirow{2}{*}{$\begin{array}{l}\text { Aramid } \\
\text { fiber }\end{array}$} & $\mathbf{5 0 0}$ & 0.12021 & 311.89 & 0.0039865 \\
\cline { 2 - 5 } & $\mathbf{5 5 0}$ & 0.18032 & 467.84 & 0.0059798 \\
\hline
\end{tabular}

\subsection{Buckling analysis of isogrid structure}

Buckling analysis of the isogrid structure was conducted using ANSYS software for three different materials, namely, carbon fiber, e-glass fiber and aramid fiber. Figure No. 8,9 and 10 show the total deformation induced in the isogrid structure made up of aramid fiber materials at various loads like $250 \mathrm{~N}, 500 \mathrm{~N}$ and $750 \mathrm{~N}$. 

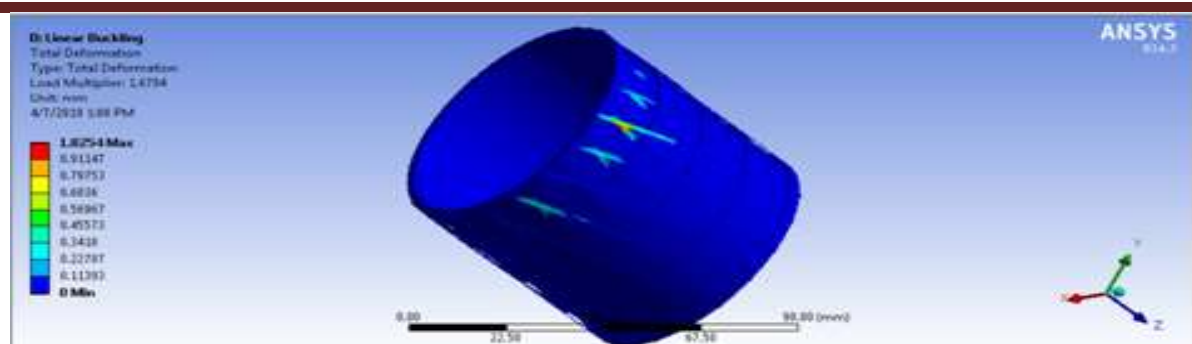

Fig No. 8: Total deformation for Aramid fiber at a load of $250 \mathrm{~N}$
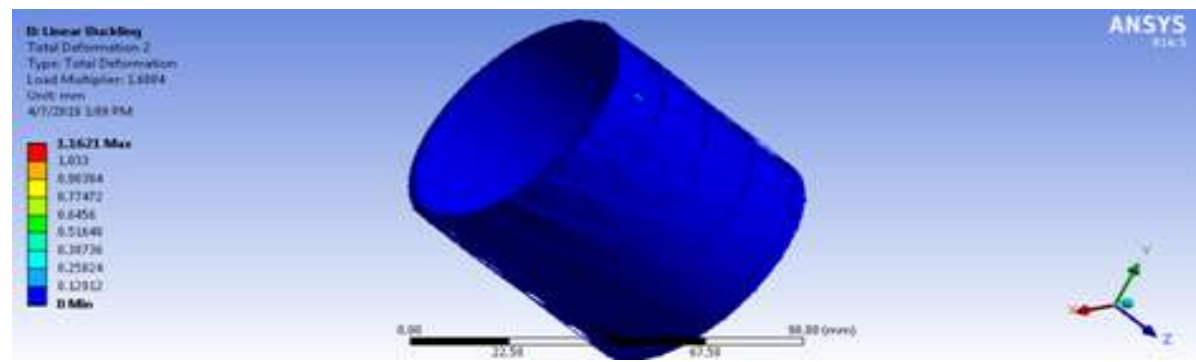

Fig No. 9: Total deformation for Aramid fiber at a load of $500 \mathrm{~N}$
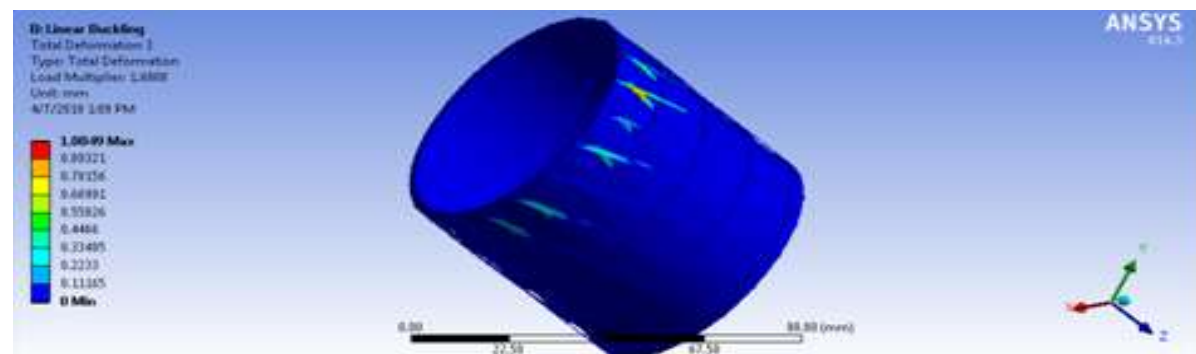

Fig No. 10: Total deformation for Aramid fiber at a load of $750 \mathrm{~N}$

Table No. 3 display the results of buckling analysis of isogrid structure with different materials like e-glass fiber, carbon fiber and aramid fiber.

Table No. 3 Results of Buckling Analysis

\begin{tabular}{|c|c|c|}
\hline Material & $\begin{array}{c}\text { Total } \\
\text { Deformation(mm) }\end{array}$ & $\begin{array}{c}\text { Load } \\
\text { Multiplier }\end{array}$ \\
\hline \multirow{3}{*}{$\begin{array}{c}\text { E-Glass } \\
\text { Fiber }\end{array}$} & 1.0249 & 1.3298 \\
\cline { 2 - 3 } & 1.1637 & 1.331 \\
\hline \multirow{2}{*}{$\begin{array}{c}\text { Carbon } \\
\text { Fiber }\end{array}$} & 1.0046 & 1.3309 \\
\cline { 2 - 3 } & 1.259 & 1.3049 \\
\hline \multirow{3}{*}{$\begin{array}{c}\text { Aramid } \\
\text { Fiber }\end{array}$} & 1.1636 & 1.3051 \\
\cline { 2 - 3 } & 1.0048 & 1.3059 \\
\cline { 2 - 3 } & 1.0254 & 1.6794 \\
\hline \multirow{2}{*}{} & 1.0049 & 1.6804 \\
\hline
\end{tabular}

It can be observed from the table that the total deformation for aramid fiber material is the least when compared to e-glass fiber and carbon fiber. Because of the superior properties 
exhibited by aramid fiber material in comparison to others during buckling analysis, it was concluded that aramid fiber material is the best suitable material for fabricating an isogrid structurefor aerospace applications.

\section{CONCLUSION}

In this research work, experiments were carried out to evaluate the strength of the isogrid cylinders with different materials and various loads like $250 \mathrm{~N}, 500 \mathrm{~N}$ and $750 \mathrm{~N}$. Static and buckling analysis was conducted to determine the deformation, stress, strain and buckling load factor. Modeling is performed using ANSYS design modeler parametric software and analysis is done using ANSYS.By observing the static and buckling analysis results, it was determined that the aramid fiber material exhibited the least value of deformation, stress and strainwhen compared to e-glass fiber and carbon fiber. Hence it was concluded that the aramid fiber material is the best suitablematerial for fabricating anisogrid structurefor aerospace applications.

\section{REFERENCES}

[1] Huybrechts, S. M., Meink, T.E. Wegner, P.M., Ganley, J.M. 2001 "Manufacturing theory for advance grid stiffened structures" Composites: Part A, 33, 155-161(2002).

[2] Mcdonnell Douglas, Astronautics Company: Isogrid Design Handbook, NASA CR124075. Huntington Beach (1973).

[3] Kim, T.: Fabrication and testing of thin composite isogrid stiffened panel, Vol. 49, Composite Structures (2000).

[4] A Güemes, J.M: Menendez 'Fibre Optic Sensors' Chapter 3 of the book 'Structural Health Monitoring', ed. by Balageas, Fritzen, Güemes, Wiley(2008).

[5] A. Güemes, A. Fernandez-Lopez, B. Soller "Optical fiber distributed sensing, Physical principles and Applications", Structural Health Monitoring, vol 9, n3 (2010). 